\title{
Derecho aduanero \\ DE SIDOROV VICTOR NIKIFOROVICH, MOSCÚ, IURAIT, 2014
}

\section{Elena Victorovna SIDOROVA ${ }^{1}$}

El derecho aduanero moderno es complejo y al mismo tiempo, constituye una rama jurídica que se desarrolla impetuosamente. La legislación aduanera de la Federación Rusa, fundamentada inicialmente en el Código Aduanero de 1993, y posteriomente en el Código de 2003, ha evolucionado y conformado una nueva legislación aduanera que funciona ya no solo en Rusia, sino en todo el territorio de la Unión Aduanera, el cual ademas incluye a Kazajistan y Bielorrusia.

Como consecuencia de dichas transformaciones, han sufrido una modernización esencial los ordenamientos legales aduaneros, no sólo en la Federación Rusa, sino también en otros Estados - como los participantes de la Unión Aduanera (Eurasia), Bielorrusia y Kazajistán. El Consejo de la Unión Aduanera (Eurasia), el 27 de noviembre de 2009 emitió el "acuerdo sobre el Código de la Unión Aduanera”, mediante el cual dicho Código fue investido con un mayor valor jurídico, estableciéndose una nueva base normativa de conformidad con estándares internacionales.

En esta relación el autor ${ }^{2}$ en el trabajo examina las tendencias modernas de la regulación normativa de las relaciones jurídicas aduaneras, el nivel nacional de los estados-miembros de la unión Aduanera, y el nivel supranacional, que en la actualidad es un problema poco estudiado.

Estos y otros cambios, contribuyen a una necesidad creciente de especialización de las y los juristas y economistas interesados en la esfera de las aduanas. La integración de la Federación Rusa en la Unión Aduanera (Eurasia), y en la Organización Mundial del Comercio (OMC) ha reforzado la tendencia indicada de manera exponencial. En este sentido, el libro del Doctor V.N. Sidorov «Derecho Aduanero» es oportuno y merece la atención respecto al estudio de las preguntas más significativas y problemáticas de la regulación jurídica que implica el traslado de mercancías a través de la frontera de la Unión Aduanera.

Dicha obra, que se ha reeditado en seis ocasiones, incluye el curso academico que refleja el estado de la más reciente legislación en la materia. Contiene las consultas sobre las prescripciones, así como recomendaciones normativas de situaciones concretas. La edición fue

\footnotetext{
1 Doctorante en Derecho por el Instituto Científico del Tribunal de Cuenta de la Federación Rusa y Licenciada en Derecho por la Universidad de Derecho del Ministerio de Justicia de la Federación Rusa. Correo electrónico: sve-evs@yandex.ru

2 Doctor en Derecho y Doctor en Filosofía. Profesor de la Universidad Estatal de Moscú M.V. Lomonosov, de la Universidad financiera al Gobierno de la Federación de Rusa, Juez del Arbitraje a fondo «Oficina Jurídica» para el permiso de las disputas civiles. Es autor de diversos libros y artículos, entre los que se encuentran más de 80 trabajos científicos. Ha impartido diversos cursos y conferencias sobre Derecho Aduanero, Derecho Internacional Privado, Derecho Empresarial, y Regulaciones jurídicas de las relaciones económicas exteriores.
} 
preparada con base en el análisis de los tratados internacionales, documentos de las organizaciones internacionales, doctrina jurídica, usos comerciales y la práctica judicial.

El contenido del manuscrito corresponde en gran medida a los requerimientos que debe de contener un curso académico, el cual incluye además de sus once capítulos, diversas preguntas didácticas y tareas; literatura recomendada; un diccionario terminológico, e incluso el programa de estudios de la asignatura. Es importante señalar que además de manera complementaria, se adjunta a cada capítulo del libro, un catálogo extenso de bibliografía reciente. En el libro se encuentran problemas de estudio relacionados con el derecho aduanero tales como: su objeto, método, nociones básicas, fuentes del derecho, la situación jurídica de los sujetos principales de las relaciones jurídico-aduaneras, entre otros tópicos relevantes de la asignatura.

Otra de las cualidades significativas del texto, es que su autor de manera minuciosa ha desarrollado temas que habitualmente otros materiales didácticos no abordan. Por ejemplo, en el capítulo 3 denominado "sujetos del derecho aduanero", además examinarlos, profundiza en las funciones de los órganos aduaneros de la Federación Rusa, vinculadas con la realización del control aduanero, de divisas, de transporte, y de exportación, así como la actividad internacional de dichos órganos.

Otro ejemplo, lo encontramos en el Capítulo 4 «Sujetos del derecho aduanero dotados a los poderes estatales», donde el jurista no se limita a enumerar las características generales de los sujetos indicados, sino que de manera más detallada (con las respectivas referencias a la legislación), comenta los rasgos de la reglamentación jurídica y creación de las actividades de transportación, almacenista temporal, propietario de almacén de aduanas, y de propietario de tiendas libres de impuestos.

Al desarrollar el tema de la regulación aduanera-jurídica en lo relativo al traslado de mercancías a través de la frontera de la Unión Aduanera, el autor menciona hechos interesantes del proceso de formación y desarrollo de los institutos del derecho aduanero, realiza un análisis comparativo de las normas jurídicas de los estados-miembros de la Unión Aduanera, y muestra la intercomunicación del derecho aduanero con otras ramas del derecho ruso.

Es indudable la importancia que reviste la preparación y actualización de las y los profesionales en la esfera de las aduanas, donde es relevante además del derecho fiscal, la asimilación de una serie de prácticas y habilidades, que harán posible la superación de la ruptura existente entre la teoría del derecho aduanero y su práctica. Por ello, otro rasgo que distingue al libro «Derecho aduanero» son sus ejercicios prácticos, que lo convierten en un importante recurso didáctico, único en su tipo.

Es importante hacer notar que de acuerdo con el Fondo Monetario Internacional, Rusia ha entrado en un período de recesión, por lo que cada día es más dependiente de importaciones de productos industriales y/o de productos manufacturados y en general de la producción de los Estados extranjeros, incluyendo a México. Bajo estas circunstancias, México tiene una serie de oportunidades para exportar productos manufacturados en virtud de las múltiples necesidades y el aumento de la crisis económica en Rusia.

Por lo anterior, el conocimiento integral del derecho aduanero se ha convertido en fundamental para los estudiosos del Derecho y la Economía, quienes serán cada vez más solicitados debido al contexto descrito. En este tenor, el libro escrito por el jurista ruso V.N. Sidorov representa una aportación de mucha utilidad. 